\title{
JOGO LIVRE: ANALOGIAS EM TORNO DAS 17 REGRAS DO FUTEBOL
}

\author{
Luiz Henrique de Toledo \\ Universidade Federal de São Carlos - Brasil
}

Resumo: O tema central desse ensaio é a análise das regras do futebol à luz de algumas teorias sociais que subsidiam, explícita ou implicitamente, inúmeras abordagens sobre o fenômeno esportivo. Manipulando o sumário do livro de regras, e impondo três deslocamentos conceituais de inspiração estruturalista, estrutural funcionalista e configuracional, respectivamente, os argumentos aqui desenvolvidos procuram recolocar o núcleo mais infra-estrutural do futebol, concebido no conjunto de suas regras, e que está na base do entendimento do futebol como um esporte moderno, dentro de um movimento comparativo mais amplo, fundamental para a consolidação de uma proposta de antropologia do esporte.

Palavras-chave: antropologia do esporte, futebol, futebol-arte, regras.

Abstract: The central topic of this essay is the analysis of football (soccer) rules in the light of social theories which, implicitly or explicitly, subsidize several approaches of the phenomenon of sports. By handling the summary of the rule book and setting three conceptual shifts of structuralist, funcional-structuralist and configurational inspiration, respectively, the reasoning developed here aims to relocate the infrastructural nucleus of football (soccer) conceived from the perspective of the whole set of its rules and which is at the basis of an understanding of football (soccer) as a modern sport, in a larger comparative movement which is fundamental to the consolidation of a proposal of an anthropology of sports.

Keywords: anthropology of sports, magic football, football, rules.

Este texto, que toma a forma de um ensaio, procurará oferecer alguns insights a respeito da relação entre regras de jogo e interação social à luz de alguns aportes teóricos comumente utilizados no campo da antropologia e sociologia do esporte. O intento, que girará em torno de exercícios de analogia, 
mais do que comprovação empírica de hipóteses, será enfocar as regras do futebol dentro daquilo que elas podem contribuir como crítica metodológica. Concebidas como um núcleo permanente do fenômeno esportivo, não raramente elas têm aparecido na produção acadêmica como um objeto pouco permeável ao exercício da alteridade, compreendidas como um fato "estável", quando não universalizado, de baixo rendimento analítico se comparado às outras representações que tem povoado os trabalhos acadêmicos; quando muito, resvalam e mimetizam o domínio das ideologias e das noções igualitárias que permeiam as crenças e valores de nossos próprios sistemas normativos.

O fato incontestável da existência de uma contigüidade sócio-histórica dos fenômenos esportivos com as sociedades ocidentais, como demonstram inúmeros trabalhos já consagrados, ${ }^{1}$ e tantos outros mais, acabou por persuadir muitos investigadores da necessidade de se debruçar sobre o caráter identitário manifesto das práticas esportivas: a particularidade do ciclismo para os franceses, a prática do pólo na constituição da identidade masculina argentina, o "caráter” espanhol expresso nas corridas etc. E, naquilo que nos concerne, em que pesem as ênfases, histórica, ensaística ou sociológica dos trabalhos, a questão nacional tornou-se muito premente no tratamento dado ao futebol brasileiro e aos seus temas correlatos.

Não se deve subestimar, obviamente, a relevância sociológica da relação entre processos identitários e os esportes, mas retomá-la sempre como condição a priori para demonstrar a relevância de certos recortes empíricos seria encorajar uma visão essencialista e redutora do fenômeno. E a busca por uma identidade substantiva pode perder de vista a percepção dinâmica da alteridade como acesso mais amplo aos propósitos comparativos futuros.

Assim, abstraídos os contextos empíricos que se somam numa bibliografia hoje mais consistente, é no suposto formalismo das regras que este ensaio se aterá, não como mero exercício intelectualista, mas para insinuar, ainda que preliminarmente, certos impasses que, rotinizados nas perspectivas etnográficas

${ }^{1}$ Os trabalhos de sociologia histórica de Norbert Elias são muito explorados do ponto de vista das abordagens que aproximam o advento dos esportes aos desenvolvimentos das sociedades ocidentais, sobretudo a partir do século XIX. Mas podemos observar tais proximidades em referências diversas, que tratam dos fenômenos lúdicos modernos de vários pontos de vista, por exemplo Venblen (1965), Huizinga (1993), Caillois 1988), Gay (1995). Para o contexto brasileiro, de uma perspectiva histórica, vale a consulta a Pereira (2000).

Horizontes Antropológicos, Porto Alegre, ano 14, n. 30, p. 191-219, jul./dez. 2008 
e sociológicas, acabam por ocultar novos problemas que poderiam ser retomados nos textos de maior fôlego empírico.

\section{De regras, formas, estilos e representações do jogar}

As regras que estabelecem os parâmetros da disputa e as formas coletivizadas do jogar que instruem as performances em campo consistem nas dimensões mais imediatas de internalização, prática e vivência continuada de uma modalidade esportiva como o futebol. A partir dessas instâncias "infraestruturais”, formulei, em outro trabalho, algumas hipóteses no intuito de verificar que o processo de formação das representações em torno desse esporte fixadas nas expressões nativas, compartilhadas tanto no senso comum quanto no métier acadêmico, "futebol arte”, "futebol espetáculo", "futebol força”, "futebol de resultados” etc. -, demandava uma análise mais tópica desse conjunto de preceitos codificados e institucionalizados. Um conjunto que perpetua a modalidade esportiva, alargando e conferindo um poderoso nexo de reprodução e continuidade à prática (Toledo, 2002a).

Assim, parafraseando Mauss (1974, p. 198), regras, formas de jogo e representações sociais "tudo se mistura", ${ }^{2}$ isto é, constituem uma moldura estrutural, seja em termos normativo e funcional, e também simbólico e cognitivo, por onde se expressam e perpetuam culturas esportivas diferenciadas. A análise do futebol, e de inúmeros fenômenos esportivos, pela antropologia do esporte deve levar em conta o caráter sintético dessas três dimensões, que chamei alhures de "naturezas" do jogo.

Vale ressalvar, entretanto, que esta moldura estrutural não pode ser tomada como um arranjo harmonioso ou imediatamente articulado, algo que até pode ocorrer em outras modalidades esportivas, fazendo coincidir, em maiores proporções, regras, performances e resultados. ${ }^{3}$ As regras e as formas do

2 Ao tratar da problemática do corpo como um novo acesso ao conhecimento antropológico, Mauss observa: "no fundo, corpo, alma, sociedade, tudo se mistura [...]".

3 A busca pelos resultados em algumas modalidades esportivas, o que implica no adestramento e execução maximizada das técnicas necessárias para atingir tal intento, é a síntese entre tais técnicas corporais e as regras que presidem a modalidade, quer dizer, o melhor cumprimento das regras levará a uma maior performance. Em outras modalidades o cumprimento das regras não necessariamente se soma à performance, como parece ser o caso do futebol, aliás, muitas vezes burlam-se as regras para atingir certos objetivos dentro do jogo.

Horizontes Antropológicos, Porto Alegre, ano 14, n. 30, p. 191-219, jul./dez. 2008 
jogar estão em permanente disjunção em virtude das determinações materiais e simbólicas que incidem tanto sobre as performances quanto sobre as representações engendradas no domínio do futebol. A cada variação na sensibilidade e disposição para a prática do jogo, que pode ser de ordem econômica, política, ${ }^{4}$ moral ou tecnológica, alteram-se as formas do jogar e a percepção que se tem dele, expondo a dimensão menos arbitrária contida nas regras às constantes demandas por mudanças.

Neste jogo livre, especifico o universo das regras, incorporando reflexões realizadas anteriormente, com o propósito de rediscutir algumas das análises teóricas sobre o fenômeno esportivo e as possíveis aproximações que se podem estabelecer entre teoria social com a teoria nativa do esporte, pensada aqui no conjunto de suas regras mais explícitas e codificadas. Creio que a menção às regras, tal como aparece num circuito importante de interpretações sobre o futebol, mereceria um tratamento menos alusivo, que muitas vezes é refém de uma opção metodológica que definiria aqui como unidirecional, na medida em que, não raramente, impõe uma excessiva autonomia à sua eficácia como um corpus coerente de preceitos formais que definem a prática do esporte.

Observações pioneiras e mais pontuais sobre as regras em trabalhos antropológicos podem ser verificadas, por exemplo, em Baêta Neves (1982, p. 52), que destaca o caráter predominantemente “defensivista” desses preceitos, ou mesmo em Vogel (1982, p. 79), que observa, mas não desenvolve uma interessante separação das regras em "elementos do jogo" e "processo do jogo". Ambas as abordagens podem ser colhidas em Universo do Futebol, coletânea cujo caráter de marco bibliográfico nos estudos sobre futebol é bem conhecido (DaMatta et al., 1982). Voltaremos mais adiante a uma das teses centrais que percorre os textos dessa coletânea, a saber, a potência igualitária emanada das regras.

De qualquer forma, procuro chamar a atenção para um exercício em torno das propriedades e relações internas que as regras poderiam estabelecer

${ }^{4}$ Como exemplo, vale a pena consultar a hipótese de Florenzano (2003) que especifica, no contexto de um movimento que ficou conhecido por "Democracia Corinthiana" (1982-1984), de que modo um conjunto de jogadores, notadamente o lateral Wladimir, o meio campista Sócrates e o centro avante Casagrande, alteraram seus estilos individuais de jogar, mas também toda uma marca coletiva assentada no estilo de jogo denominado de "raça corinthiana", em consonância a uma maior adesão, compreendida pelo autor como 'práticas de liberdade', à esfera das reivindicações pela redemocratização, movimento deflagrado na primeira metade dos anos 1980.

Horizontes Antropológicos, Porto Alegre, ano 14, n. 30, p. 191-219, jul./dez. 2008 
entre si, ampliando a complexa dinâmica das práticas significantes que balizam e ao mesmo tempo constituem as representações sociais delas emanadas. É claro que, no limite, disposição, rotina, movimentação e destreza corporal dos jogadores em campo, sintetizadas nas chamadas formas de jogo, bem como as regras que viabilizam e também estabelecem os limites possíveis para essas condutas, já consistem em representações cristalizadas e instituídas num nível mais propriamente normativo. Pois, tal como nos adverte Durkheim (1970, p. 26), “uma representação não se produz sem agir sobre o corpo e o espírito".

Entretanto, embora tendamos a salientar o caráter espontâneo, o potencial individual e corporal dos jogadores, algo que alimenta a autopercepção que toma o futebol brasileiro por "artístico”, “mágico”, “individualista”, não podemos reduzir as representações sociais às sensações de natureza intuitiva de cada jogador, condicionadas as compleições ou aspectos físicos ou mesmo psicológicos, tal como se propagaram, no imaginário social, as representações em torno de um número expressivo de excepcionais jogadores (como no "assimétrico ou torto” Garrincha, no "esguio” Didi, no “magro” Sócrates ou no "baixinho” Romário). As disposições para a prática do "futebol arte” deveriam ser observadas para além das faculdades da sensibilidade, em regiões do espírito mais estáveis, uma vez que, de acordo com as lições de Durkheim (1970), ${ }^{5}$ existiriam fora de nossas sensações corporais ou representações individuais.

Portanto, como primeira observação, regras, formas de jogo e, obviamente, as categorias "futebol arte", "futebol força” etc., estão sendo assumidas aqui como variações de mesma natureza, representações coletivas, apreendidas na multiplicidade de manifestações e expressões de um fenômeno único. Conseqüentemente devemos evitar certas hierarquizações temáticas, que tendem a privilegiar uma abordagem do futebol, ou sobre outra modalidade qualquer, como um "sistema imaginário", deslocando os significados embutidos em temas mais à margem, tal como um estudo sistemático sobre as regras. Assim, podemos iniciar uma aproximação analítica com o futebol de qualquer lugar, bastando ficar atento às propriedades e relações entre as várias dimensões que o compõem, quer dizer, as regras também possuem plasticidade simbólica, obviamente por serem, elas mesmas, representações sociais. Abre-se

\footnotetext{
Para uma análise teórica sobre a problemática das representações no pensamento durkheimiano consultar Pinheiro Filho (1996).
} 
com isso a possibilidade de uma abordagem conceitual mais plural, no sentido de verificar os limites, os alcances e as opções que estão na base de algumas das interpretações mais correntes.

Enquanto as regras variam mais lentamente, conferindo à referida modalidade esportiva uma maior estabilidade na condução do ethos do jogo, fixando e compartilhando valores que se crêem universais e homólogos aos tantos credos e valores normalizados das sociedades que inventaram os esportes, as formas do jogar são definidas mais livremente e ao sabor do domínio das disposições simbólicas disponibilizadas em cada escola (“cultura”) esportiva ou contexto específico. Problematizar a dimensão das regras dentro de um fenômeno tão específico como o futebol não implica em renunciar totalmente a um debate de maior fôlego no interior das ciências sociais, particularmente na antropologia, que diz respeito ao estatuto da condição arbitrária das formas da vida humana associada como fundamento de nossa singularidade enquanto espécie. $\mathrm{O}$ universo de regras, que para muitos autores confere à humanidade a sua unidade ontológica, está no centro de um debate epistemológico cujos desdobramentos podem ser verificados nas mais diversas correntes teóricas que organizaram o material etnográfico e o projeto comparativo que anima a disciplina.

Desdobrada em várias antinomias, a antropologia contempla, de maneira reiterativa, as análises emolduradas ora pelo conceito de "sociedade”, e aí a noção de regra adquire um estatuto normativo que incide sobre a natureza morfológica dos grupos sociais em interação, ora pelo conceito de "cultura", em que as regras aparecem como princípios simbólicos ordenadores das manifestações e experiências universalizadas. ${ }^{6}$ A alusão ao domínio das regras do futebol em trabalhos acadêmicos parece resvalar nesse movimento epistemológico pendular e mesmo naquelas abordagens que, explicitamente, reivindicam um viés mais culturalista ou simbólico. Tal movimento oscilante insinua-se quando são abordadas as regras, fazendo com que a análise deslize para uma chave explicativa mais tutelada, digamos assim, pelo viés normativo embutido num conceito mais próximo ao de sociedade.

${ }^{6}$ Para um balanço sucinto de autores e correntes teóricas consultar Velho e Viveiros de Castro (1978) e Viveiros de Castro (2002).

Horizontes Antropológicos, Porto Alegre, ano 14, n. 30, p. 191-219, jul./dez. 2008 


\section{Regras "frias" e "quentes"}

Proponho como exercício metodológico fazer uma leitura da disposição das regras a partir de uma análise do sumário dos livros e manuais que as prescrevem. Dependendo da opção teórica disponibilizada, indico as clivagens ou fusões que repercutem em conjuntos classificatórios de relevo para cada problemática específica. A intenção é esboçar um mapeamento obviamente provisório de algumas teorias sociais que são tomadas como aportes conceituais que, em troca, respondem a demandas metodológicas variadas. São três os exercícios em que imponho algumas simetrias classificatórias ao conjunto heteróclito das regras. Antes de tudo, porém, precisamos (re)conhecê-las.

São dezessete as regras que viabilizam, tanto do ponto de vista competitivo quanto do ponto de vista da fruição estética, uma partida de futebol, formando um conjunto de preceitos distribuídos da seguinte maneira nos manuais e livros de regras:

I - o campo de jogo; II - a bola; III - número de jogadores; IV - equipamento dos jogadores; V - árbitro; VI - fiscais de linha; VII - duração da partida; VIII - início da partida; IX - bola em jogo e fora de jogo; X contagem de gols; XI - impedimento; XII - infrações e indisciplina; XIII - o tiro livre; XIV - pênalti; XV - arremesso lateral; XVI - tiro de meta e XVII, tiro de canto.

Um exame mais atento das regras trairia, digamos assim, uma dada noção de homogeneidade e coerência que geralmente se quer atribuir ao conjunto exposto acima. Podemos notar nesta disposição uma primeira classificação significativa dada pela organização das regras em questão, que oculta um dualismo peculiar. Dualismo presente em muitos trabalhos sobre futebol que tensionam dicotomias conhecidas como ritual e jogo; jogo e esporte, ritual e competição e, extrapolando em muito o campo esportivo, sociedades "simples" e "complexas".

Trata-se, pois, de encontrar no conjunto das regras do futebol uma classificação igualmente arbitrária que, por sua vez, também se configura como regra e que evoca o plano de uma totalidade coerente que se quer atribuir aos preceitos que estabilizam a referida modalidade esportiva. Esse sentido de totalidade pode ser observado já nas primeiras páginas das publicações destina- 
das à explicação das regras. Logo na introdução de um desses manuais, lê-se: "as alterações [nas regras, ao longo dos mais de 130 anos] são bem poucas, uma vez que [as regras] são quase perfeitas, tendo-se que apenas aplicá-las com mais padronização" (Franciscon, 1996, p. 13, grifo meu).

"Perfeição" alude à manifestação de uma atitude subjetiva cara às formações sociais de tradição ocidental, na medida em que embute o pressuposto da autonomia das regras do tecido social como "mais um elemento de nossa consciência moral”, tal como nos adverte Lévi-Strauss. ${ }^{7}$ Nesse sentido, as regras supõem a consciência que se empresta ao jogo, tornando a expressão de sua seriedade e reorientando formas lúdicas da sociabilidade dentro do conjunto de forças simbólicas que ditam a configuração de nossas sociedades, e que é diversa das formas de expressões lúdicas existentes em outras sociedades mais afastadas da tradição ocidental no tempo e no espaço. Lévi-Strauss contrasta as sociedades ocidentais, ante o domínio da história como um devir ou meta-processo que anima a evolução natural, com as sociedades "sem história” que, subjetivamente, inclinam-se a negá-la em nome de uma permanência temporal e/ou espacial de suas cosmologias como legitimadoras do socius.

Certamente foi Lévi-Strauss um dos antropólogos que mais avivou o debate entre história e estrutura, impondo à história e aos processos sociais por ela encadeados uma dúvida metodológica em relação a sua ambição heurística. Ao rebater certas considerações que afirmam ser impossível captar estruturas estáveis sem antes compreender os processos subjacentes às formações sociais, respondeu com um princípio do método que ambicionou universalizar:

[...] as estruturas apenas se mostram a uma observação feita de fora. Esta, ao contrário, não pode mais captar os processos, que não são objetos analíticos, mas a forma peculiar em que uma temporalidade é vivida por um sujeito. O que equivale a dizer, de um lado, que não existe processo senão para um sujeito comprometido em seu devir histórico ou, mais exatamente, no grupo de que é membro e, por outro lado, que, num grupo dado os sujeitos são tão numerosos e tão diferentes uns dos outros - que existem subgrupos de identificação: para um aristocrata e para um revolucionário a revolução de 1789 não é o mesmo processo; não existe um "meta-processo" que integre estas experiências irredutíveis. Ele existe para um pensamento historicamente posterior e que

7 Conforme Eribon e Lévi-Strauss (1989, p. 161).

Horizontes Antropológicos, Porto Alegre, ano 14, n. 30, p. 191-219, jul./dez. 2008 
corresponde à ação de um grupo que, por sua vez, insere a revolução dentro de sua própria perspectiva histórica. (Lévi-Strauss, 1971, p. 38). ${ }^{8}$

Em suma, vive-se a história, ou mais precisamente uma historicidade singular, mas observam-se as estruturas. Esse argumento vale para a história dos historiadores, e também para outras disciplinas que historicizam os fenômenos sociais, como parece ser o caso, mutatis mutandis, da propalada evolução "perfeita" que se quer emprestar às regras do futebol no domínio da sensibilidade nativa de seus atores sociais. ${ }^{9}$

Entretanto, é preciso salientar que captar as propriedades estruturais do conjunto de regras não implica em renunciar à ambição da reconstituição histórica, mas atentar para as historicidades singulares. Quero somente advertir com tudo isso que o futebol não tem uma história, mas várias, que passam, por exemplo, pela história ligeira das carreiras futebolísticas individuais ou pela história lenta e impessoalizada das regras. Basta ficarmos atentos para as relações dialéticas recíprocas - de simetria, contradição, oposição (Lévi-Strauss, 1979, p. 52), que se colocam no confronto dessas formas de historicidades.

As regras, se tomadas na sua homogeneidade, coerência e universalidade, caracterizariam o domínio do esporte e formam, portanto, o núcleo predominante das manifestações lúdico-esportivas encontradas nas sociedades "complexas" por oposição aos jogos anteriores ao advento "histórico" da modernidade dessas mesmas sociedades, ou ainda dos jogos rituais das sociedades ditas "simples". Contudo, parece-me que tal dicotomia, de fato, mostra-se problemática já do ponto de vista de um exame mais detido das regras, sobretudo quando submetemos todo o conjunto ao domínio "ideológico" exclusivo das sociedades complexas, tomando-o como desdobramento das normalizações peculiares e "naturais" do âmbito das organizações sociais ocidentais, como se todas as dezessete regras prestassem a corroborar, da mesma forma e intensidade, a inequívoca "natureza" esportiva dos fenômenos lúdicos dos quais os esportes se originaram.

Mas, retomando o conjunto das regras sob o crivo de "um olhar distanciado" podemos observar fissuras importantes que reclamam por uma análise

${ }^{8}$ Penso particularmente em Lefort (1990, p. 42) ao censurar formas assumidas pelos estruturalismos quando afirma que "não basta elucidar as regras explícitas ou implícitas que tornam uma vida social possível: é preciso ainda mostrar que estas regras representam uma confirmação de relações sociais vividas pelos homens e para onde tende esta conformação [interpretar o devir]".

${ }_{9}$ Para uma análise do estatuto da História no projeto estruturalista lévi-straussiano consultar Goldman (1999).

Horizontes Antropológicos, Porto Alegre, ano 14, n. 30, p. 191-219, jul./dez. 2008 
menos homogênea no que se refere a sua propalada universalidade e "perfeição” histórica, se tomada como um conjunto de preceitos encadeados serialmente. Na tensão de uma polaridade, constata-se a presença de dois subgrupos distintos: um primeiro que compreende as regras de I a VIII, e um segundo, da IX a XVII. No primeiro, deparamo-nos com as regras que estabeleço como frias, e que poderiam ser circunscritas ao domínio da previsibilidade, da mensurabilidade, de atores e coisas disponíveis, dispostos num enquadramento espacial e temporal definidos na suas finitudes. Regras que aludem a uma dimensão, digamos, mecânica, preponderantemente estrutural e que dizem respeito mais exatamente às disposições sobre as quais se eleva o segundo subconjunto. Trata-se de uma "condição", de um "estado" permanente para o jogo. Alguns indivíduos, uma bola, um recorte espacial bastam para que esta configuração, este estado inicial potencialize uma determinada interação lúdica que, por ventura, pode ser chamada de partida, ainda que faltem outros elementos desse conjunto (um árbitro, fiscais, uma rígida cronometragem, etc.). ${ }^{10}$

No segundo conjunto, por oposição e contraste, e que poderíamos denominálo de núcleo das regras quentes, compreenderiam aquelas que legislam sobre as várias interações possíveis, mais próximas de um ethos competitivo e da condição subjetiva com que vislumbramos a natureza de nossas sociedades “complexas”: interação contendora entre os jogadores, jogadores com árbitros e fiscais de linha, posse e "pilhagem” dos objetos disponíveis, usos de uma temporalidade que se escoa e apropriação desigual dos espaços do campo. Portanto, evocam a idéia de movimento, "regras históricas", da ordem dos eventos que se encadeiam, daí a forte presença da imprevisibilidade como motor dessa interação, necessariamente processual. No geral, são justamente estas as que mais sofreram e sofrem mudanças ao longo do processo de fixação. Basta citar a lei do impedimento, regra XI, como um exemplo notório encontrado nos manuais. ${ }^{11}$

\footnotetext{
${ }^{10}$ Excetuando as partidas oficiais, joga-se futebol em temporalidades ou espacialidades bastante variadas, o que não invalida, de todo modo, a necessária existência dessas duas condições fundamentais para que ocorra uma partida. Claro que estou desprezando aqui os jogos juvenis cotidianos que se aproximam do futebol ("rebatida", "bobinho", as "peladas" de praia e todos os jogos de improviso), aqueles jogados virtualmente ou com maquetes (futebol de botão), circunstâncias em que as dimensões da temporalidade e da espacialidade são bastante subvertidas.

${ }^{11}$ A respeito das mudanças nas regras, consultar Toledo (2002a) e o modo como tais alterações repercutem na formação dos estilos de jogo.
}

Horizontes Antropológicos, Porto Alegre, ano 14, n. 30, p. 191-219, jul./dez. 2008 
Há que se verificar também o nível de aquiescência que as regras frias evocam se contrastadas às regras quentes. As regras quentes, de outro modo, legislam sobre os movimentos e a trama dos jogadores e expressam no plano dos divertimentos nossa consciência sobre o devir das "sociedades quentes" e o modo como internalizamos a historicidade como processo social disjuntivo. Estas impõem às condições da partida um rol de recomendações que tentam conter os níveis de ruptura e violência instaurados no embate dos atores. Observar, por exemplo, a questão das infrações, qualificadas num nível estratificado em "morais”, "bruscas”, "bruscas graves” e "violentas", na regra XII.

As relações que estabeleço entre um "estado de jogo" e um "processo de jogo", entre as regras frias e as regras quentes devem ser compreendidas tão somente como uma estratégia metodológica, tal como explicita Lévi-Strauss, autor que primeiro propôs este sistema de contrastes. Nos seus termos:

Quando falo de "sociedades frias" e de "sociedades quentes", tenho em vista casos limites. Disse, escrevi, repeti centenas de vezes que nenhuma sociedade é absolutamente "fria" ou "quente". Essas são noções teóricas de que necessitamos para formular nossas hipóteses. As sociedades empíricas distribuem-se ao longo de uma linha em que nenhuma delas ocupa os pólos. (Eribon; Lévi-Strauss, 1989, p. 160).

Trata-se de uma classificação que repercute nas formas de interação social denominadas de jogo e esporte, tão cara a muitas das discussões sobre a natureza dos fenômenos competitivos nas sociedades ocidentais em contraste ao universo dos jogos ou de alguns rituais das sociedades ditas "tradicionais".

DaMatta (1982), por exemplo, orientou parte de seu ensaio sobre futebol a partir da oposição jogo e esporte, mas num insight mais propriamente etimológico, tentando aproximar linguagem e cultura. Em relação às regras adotou o ponto de vista universalizante como princípio regulador de experiências igualitárias embutidas nas regras. Nesse sentido, ao menos no tocante a análise das regras, escapou-lhe o movimento de estranhamento, na medida em que as associou quase que imediatamente ao credo igualitário contido no universo impessoal que permeia nossas representações e ideologias: formas de consciência da nossa sociedade. Esta clivagem à Lévi-Strauss imposta ao conjunto das regras poderia orientar nossas pesquisas no sentido de que possamos problematizar em todos os níveis a dicotomia rígida estabelecida entre jogo e esporte e outros desdobramentos de mesma série. 
Elementos estruturais que definem uma dinâmica de um jogo ou de um ritual (temporalidade, espacialidade, o acaso, pensando especificamente que uma partida inicia-se por intermédio de um sorteio, regra VIII, a última das regras frias), constam dos fundamentos das regras do futebol, mas não somente nele, tal como observamos em muitas outras modalidades esportivas assemelhadas. São alguns elementos ritualísticos que se manifestam no corpus das regras impondo um "estado" e uma mobilização permanente para o extraordinário e para a especulação sobre os sentidos do jogo que, certamente, extravasam os limites da nossa consciência histórica moderna calcada na busca de resultados tangíveis e escapam à instrumentalidade da competição como sendo somente o domínio do ganho e do lucro.

Penso no "acaso" no sentido da intromissão do máximo de arbitrário que se possa esperar no conjunto das regras, espécie de estopim de uma narrativa mítica revivida no plano ritual. Afinal, um rito extravasa as "razões práticas" mais aparentes para dar início a um movimento especulativo sobre a existência de homens e grupos. $\mathrm{O}$ ato residual do sorteio previsto nas regras, que viabiliza o início de uma partida de futebol, passa ao largo da natureza competitiva e dos desempenhos esperados e não é casual que indivíduos ilustres sejam freqüentemente convocados para darem o pontapé inicial em partidas que ganham algum tipo de relevância simbólica.

Nesse contexto, as regras frias, um formalismo que legisla diretamente sobre algumas categorias do espírito humano (uma espacialidade e temporalidade específicas, a dimensão do acaso como manifestação do incontrolável, estopim de historicidade), configuram um solo comum de possibilidades de comunicabilidade e inteligibilidade com outras formas de experenciar o lúdico. Uma "brincadeira" entre amigos, daquelas onde o que menos importa é o placar ou a aferição dos desempenhos individuais, pode tranqüilamente prescindir de parte das regras quentes, mas a quase totalidade das regras frias estará presente, pois é a própria condição de possibilidade da interação lúdica.

Este pode ser um caminho interessante para se pensar na projeção que o futebol, ${ }^{12}$ e porventura outras modalidades esportivas, vem adquirindo nas sociedades mais marcadamente não ocidentalizadas, tais como alguns coletivos indígenas circunscritos ao território nacional. ${ }^{13}$ Mesmo que o caráter competi-

\footnotetext{
12 Para uma análise detida sobre os desdobramentos do chamado “futebol espetáculo" consultar Damo (2007).

${ }^{13}$ A aproximação entre futebol e coletivos indígenas pode ser bem observada em alguns trabalhos, por exemplo na dissertação de mestrado de Vianna (2002).
}

Horizontes Antropológicos, Porto Alegre, ano 14, n. 30, p. 191-219, jul./dez. 2008 
tivo das regras quentes apareça salientado nas disputas em contextos menos espetacularizados, como nas aldeias e reservas indígenas, por exemplo, e de que hoje seja comum a ocorrência dos torneios esportivos e olimpíadas indígenas como eventos que misturam jogos rituais e esportivos, tal constatação não faz dessas práticas esportivas uma atividade completamente nova. Não se trata também de um mero reconhecimento do futebol como um passatempo impositivo ou superior em relação aos rituais e divertimentos indígenas, e que estaria, desse modo, corrompendo certas tradições ou possibilitando um acesso fácil ao mundo dos brancos, mas de ver nele uma modalidade ritual, um caso particular de uma expressão mais geral que dialoga parte de seus fundamentos com a lógica ritual que experimenta a dimensão lúdica em grupo para além das determinações imediatas da vida cotidiana.

Assim, Lévi-Strauss ajuda-nos a suspeitar de uma indigenização do futebol, ${ }^{14}$ na medida em que jogo e esporte, tomados muitas vezes como províncias irreconciliáveis em nossa autopercepção, a de senso comum e histórica, guardam entre si determinadas homologias que valem a pena investigar, numa perspectiva comparativa, por meio da efetuação constante das trocas culturais. Ajuda-nos a suspeitar também que esportivizar ou ritualizar não seriam projeções mutuamente exclusivas do social. Desse modo, ao menos parte das regras traem um pouco nossa consciência histórica na medida em que podem ser extrapoladas nas infinitas formas de apreender os sentidos do esporte, como demonstram alguns trabalhos. ${ }^{15}$

\section{Futebol brasileiro, futebol-arte e futebol-forca}

Passemos a um segundo movimento arbitrário imposto às regras. Neste momento embaralho os elementos do conjunto, refazendo a classificação. Expondo-os não mais em termos "binários”, mas orientados por uma configuração societária, no sentido de aludir a uma estrutura mais empírica, porém significativa do ponto de vista de uma morfologia dinâmica que sustenta a modalidade esportiva. Se, no exercício anterior, as regras foram cindidas num par de

\footnotetext{
${ }^{14}$ Utilizo de maneira livre as argumentações de Sahlins (1997a, 1997b) sobre um processo mais geral nomeado de “indigenização da modernidade”.

${ }^{15}$ Nesse sentido o trabalho de Damo (2007) parece revelador dos sentidos multiplicadores de se experimentar os esportes.
} 
opostos de inspiração lógica, que embute no seu horizonte a perspectiva comparada, aqui passam a adquirir um caráter nitidamente mais moral e regulativo, definindo formas de permanência para as condutas individuais e coletivas na manutenção da ordem esportiva dentro de campo, com implicações analíticas mais abrangentes. Aqui as orientações teóricas certamente mudam, e sugiro que sigamos com a sinédoque e aproximemo-nos da perspectiva mais estrutural-funcional. Neste caso, o conjunto das regras passaria a ser tomado como um esqueleto ou "estrutura" do esporte, revelado como "parte" e não "potência” do objeto futebol, salientando um caráter mais normativo em detrimento de uma perspectiva simbólica.

Ou seja, no exercício anterior, com a sugestão inicial em separar o conjunto das regras utilizando as metáforas lévi-straussianas do frio e do quente, fui levado a um "binarismo" que certamente extrapolou as próprias regras, expondo os contornos de um sistema de relações que se desdobrou e se transformou em formas e níveis distintos (jogo/esporte; sociedade "simples”/sociedade “complexa”) de se pensar a natureza dessas regras. Agora, assumo a idéia de que as regras formam um núcleo resistente e que pode ser concebido como parte funcional da modalidade futebol, enunciando a problemática durkheimiana das solidariedades, tal como Radcliffe-Brown (1973) procedeu para os estudos das estruturas sociais, tomando os sistemas de parentesco como mecanismos geradores da estrutura no contexto das sociedades "simples".

O interesse é menos em elucidar um esboço de uma perspectiva "clássica”, obviamente, e salientar como inúmeras pesquisas, embora não tenham desenvolvido reflexões mais sistemáticas sobre as regras propriamente ditas, incorporaram parte dessa perspectiva na busca de categorias classificatórias mais amplas, que aparecem amiúde nos trabalhos sobre futebol. ${ }^{16}$ Desta vez, as regras formarão quatro pequenos conjuntos, desobedecendo a seqüência ordinária (serial e matemática) do sumário. Teríamos então, em primeiro lugar, as regras I; VII; IX; X e XI, reunidas dentro daquilo que chamarei de eixo espaço-temporal; o segundo grupo composto pelas regras II; IV e VIII, que dispõe sobre a cultura material do jogo; o terceiro seria aquele que prepondera as práticas individuais, composto pelas regras XIII; XIV; XV; XVI e XVII e, finalmente, o quarto grupo, organização social: III; V; VI e XII.

\footnotetext{
${ }^{16}$ Para um balanço das teorias e temáticas que abordaram o futebol sugiro o rápido apanhado bibliográfico em Toledo (2002b).
}

Horizontes Antropológicos, Porto Alegre, ano 14, n. 30, p. 191-219, jul./dez. 2008 
Semelhante ao primeiro exercício, temos aqui novamente uma configuração complexa que merece ser observada na sua filigrana. Se antes tal complexidade estava assegurada num sistema de relações simbólicas que se expandia em vários planos, aqui encontramos um sistema de relações propriamente sociológico e menos universalizante na sua ambição comparativa.
a: eixo espaço-temporal - regras I; VII; IX, X e XI
b: cultura material - regras II; IV e VIII
c: práticas individuais - regras XIII; XIV; XV; XVI e XVII
d: organização social - regras III; V; VI e XII

O grupo a (campo de jogo, duração da partida, bola em jogo e fora de jogo, contagem de gols e impedimento) poderia ser definido como a dimensão propriamente "ecológica" e remete às apropriações desiguais dos "recursos naturais" do jogo pelos times no transcurso de uma partida. Vale ressaltar que a inclusão do impedimento neste conjunto justifica-se porque ele consiste na participação mais o posicionamento dos jogadores, quer dizer, o impedimento depende da dinâmica ordenada e concatenada de posições espaciais coletivas e individuais dentro de campo.

Muitas abordagens sobre futebol priorizaram as apropriações do tempo e do espaço como dimensões vividas no esporte constituindo um domínio propriamente ritual. ${ }^{17}$ Mais uma vez, observamos o rendimento do binômio jogo e esporte, só que agora colocado numa perspectiva expressiva, na dimensão dos papéis que os agentes desempenham e não mais no nível da inteligibilidade lógica da relação entre os termos jogo e esporte. As análises do futebol como drama social são exemplos elucidativos. No contexto de um esporte tomado como ritual e jogo, que nem todos os esportes alcançam, dramatizam-se os elementos significativos que estão fora dele (indivíduos, grupos, classes, a política, questões étnicas etc.), situados na sociedade que de origem. ${ }^{18}$ No drama,

\footnotetext{
${ }^{17}$ Por exemplo, o trabalho de Moura (1998). Nele, a autora mostrará o papel que a construção do estádio do Maracanã teve na consolidação do processo identitário entre o referido esporte e a sociedade brasileira. A derrota do Brasil na copa de 1950, um grande luto ritual, consistiu na provação definitiva da popularidade do futebol entre os brasileiros. Um outro trabalho que rende à dimensão espacial a importância como um locus simbólico é Florenzano (2003).

${ }^{18} \mathrm{O}$ rendimento das análises do futebol como drama social pode ser verificado em inúmeros autores, desde as abordagens originais de DaMatta (1982).
} 
potencializam-se as normas [ou contranormas], exacerbam-se os papéis, vivese a sociedade sob a qualidade da efervescência social [e moral].

Em “cultura material” (grupo b: bola, equipamentos e início da partida) é interessante destacar a inclusão de uma regra que, em princípio, deveria estar no domínio ecológico, uma vez que legisla sobre um aspecto temporal. A rigor, uma partida tem o seu início não exatamente ao trilar do árbitro, mas no movimento da bola em direção ao campo oponente, chancelando aos jogadores o desenrolar do jogo. Observamos que, tomadas desta perspectiva, o conjunto das regras aparece como uma forma social que totaliza e confere um poderoso princípio de ordem e nexo funcional ao esporte. Cabe destacar que quando separamos as regras nos referidos conjuntos a prevalência da polaridade indivíduo/sociedade, cara à escola funcional britânica, torna-se mais evidente a partir do contraste estabelecido entre os grupos $\mathbf{c}$ e $\mathbf{d}$.

O grupo c revela mais explicitamente as regras cujo cumprimento é dado por gestos e posturas corporais individuais (o tiro livre, pênalti, arremesso lateral, tiro de meta e tiro de canto) e estão sempre relacionadas às maneiras em que uma partida deve ser reiniciada. Lembremos, por exemplo, que o pênalti não consiste na infração em si, mas numa maneira de recomeçar o jogo, ele é uma conseqüência de quem cometeu uma falta num espaço específico do campo, dentro dos limites da grande área. ${ }^{19}$

Já as regras do grupo d (número de jogadores, árbitro, fiscais e infrações e indisciplina) perpetuam as relações de primeira ordem em uma partida, geradoras da estrutura explicitada nos níveis das relações possíveis: o contato verbal e físico, a camaradagem e a esquiva, o companheirismo e a hostilidade, as relações jocosas e as advertências, as linhas combinadas de passes, impedimentos, jogadas de ataque e defesa. Formam um subconjunto das regras morais por excelência. Daí a forte presença da regra XII neste grupo, que orienta sobre as infrações e a indisciplina. A partir desse conjunto não vislumbramos ações isoladas, mas os contornos de um sistema, ou melhor, um sistema de relações, ou um sistema de jogo.

\footnotetext{
${ }^{19}$ Segundo o ex-árbitro do quadro da Fifa, Emídio Marques de Mesquita, do ponto de vista da arbitragem "o pênalti seria tão somente uma maneira de o jogo ser iniciado" (Caderno de campo, 5/11/ 1996). Nota-se o quanto essa representação se afasta da perspectiva do torcedor, que vivencia no pênalti um momento de intensa emoção.
}

Horizontes Antropológicos, Porto Alegre, ano 14, n. 30, p. 191-219, jul./dez. 2008 
Performances individuais constituem um conjunto expressivo de jogadas e influenciam na busca dos resultados e manutenção dos níveis de emoção, todavia as formas de jogo, concatenação solidária dos jogadores em campo, não "nasceram" da cobrança de um lateral ou de um pênalti, mas das interações mais complexas que continuamente são travadas e impostas por intermédio dos preceitos contidos nas regras do grupo d. Portanto, o conjunto codificado de atitudes e gestos individuais que integra o grupo c, regras de segunda ordem, está subordinado ao funcionamento do sistema prescrito na "organização social” (o grupo d). Esta divisão no interior do conjunto das regras recoloca não somente a problemática da solidariedade e a tensão existente entre a performance individual e coletiva, cuja matriz conceitual pode ser encontrada no âmago da perspectiva dualista durkheimiana entre o profano e sagrado, como também pode reiterar o embate travado entre as representações nativas "futebol força", considerado o primado do coletivismo e "futebol arte", locus do desempenho propriamente individual.

Diria novamente que as representações "arte" e "força", tão ao gosto das contendas que mobilizam os torcedores, as crônicas especializadas e os profissionais, constituem fenômenos de mesma natureza que as regras, sendo relações sociais em última análise. Portanto, não podemos negligenciar, ao problematizar as representações em questão, o domínio das regras como matriz geradora de uma estrutura que, em parte, suporta o contraste entre tais representações.

Não obstante, ao forçarmos o aparecimento desse dualismo (c e d) a partir desta classificação estrutural-funcional do conjunto das regras, notamos quão difícil seria sustentar uma dicotomia rígida entre duas formas ou representações absolutas do jogar futebol. A tensão existente entre o jogo individual e o coletivo, entre as formas mais prazerosas e as pragmáticas, aparentemente ocultas no sumário de regras, embora a subdivisão nos leve a este tipo de dualismo, deve ser observada com mais cautela.

Se, por um lado, o exercício de uma análise estrutural-funcional nos permite evidenciar no interior das próprias regras a tensão existente entre preceitos mais individuais e preceitos mais coletivos, a partir de uma divisão arbitrária que estabeleci e impus ao seu conjunto, por outro lado, torna-se mais difícil a compreensão do dinamismo que se estabelece entre jogo individual e coletivo ao longo de uma partida e seus desdobramentos num plano mais propriamente representacional. Ou melhor, se reencontramos aqui uma dada estrutura, falta 
compreender o processo e as transformações. As análises e os trabalhos sobre futebol que se utilizam amplamente das expressões "futebol-arte" e "futebolforça”, não raramente tomadas também como metáforas, deveriam ficar mais atentos aos perigos da reificação dessas categorias que, embora estabeleçam divisores classificatórios ricos do ponto de vista empírico, em termos analíticos podem acabar assumindo um dualismo rígido, caro às análises funcionais, sem muitas vezes dar-se conta disso. Há que se observar as relações e os múltiplos significados em disputa pelas definições de "força" e "arte".

"Arte" e "força” no domínio esportivo são, antes de tudo, relações sociais, fatos e valores, e devem ser captados num movimento processual, numa dinâmica contrastiva definida pelos regimes de alteridade que são estabelecidos numa perspectiva comparativa. As argumentações que repisam num registro essencializado a identidade entre futebol brasileiro - metonímia conceitual da sociedade que o vivencia em vários planos ${ }^{20}$ - e "futebol-arte" deveriam levar em conta a posição mais estrutural assumida por um terceiro termo, constitutivo desta identidade enunciada, ou seja, as representações em torno da noção de "futebol-força" como parâmetro englobado.

Associando, portanto, os três termos, "futebol brasileiro" como totalidade, e os pólos "futebol-arte" e "futebol-força”, os valores que definem os limites da identidade e alteridade estão em permanente movimento contrastivo, de aproximação e estranhamento, atualizados no plano do vivido, e que só poderiam ser apreendidos como tal num nível etnográfico, dimensão ausente neste texto. Embora não remeta nesse ensaio a inspiração conceitual dumontiana sobre hierarquia ela poderia abrir uma vertente explicativa das mais proveitosas para aprofundar esta questão: “[...]A percepção hierárquica obriga a levar em conta situações determinadas e pontos de vista particulares, distinguindo-se assim das classificações binárias simples[...]” (Bevilaqua, 2002, f. 261). Esta chave analítica permitiria compreender como, em determinadas circunstâncias, o futebol brasileiro, mesmo jogando em contrariedade à propalada “arte”, pôde amealhar vitórias, operando, ainda que momentânea e em diferentes níveis, uma inversão na assimetria de valores entre "força" e "arte".

\footnotetext{
${ }^{20}$ Muito comum observarmos na literatura científica ou ensaística a constatação, um tanto quanto óbvia, de que o brasileiro "joga” o futebol em vários planos, no domínio da cultura, no domínio da linguagem, nas representações estéticas etc. Nessa direção, o leitor poderá encontrar uma bibliografia variada num volume em forma de catálogo publicado pelo Sesc (Técnicos..., 2002).
}

Horizontes Antropológicos, Porto Alegre, ano 14, n. 30, p. 191-219, jul./dez. 2008 


\section{Regras dentro de regras}

Parto para uma última movimentação no conjunto das regras, reunindo-as novamente. Porém, não no sentido de reagrupá-las tal como na disposição original do sumário, de onde iniciei o primeiro exercício, sequer insistirei agora na organização social "clássica", que trouxe à tona a tensão entre indivíduo e sociedade e, por extensão, a problemática das categorias "futebol arte" e "futebol força" como supostas antinomias. Deslocamos a perspectiva da lógica dos pares de oposição e da perspectiva regulativa-coercitiva da visão funcional para introduzir o domínio das regras do jogo como performance e sociabilidade. Aproximamo-nos aqui de parte do modelo da sociologia configuracional proposto por Norbert Elias e o modo como problematiza o processo de interiorização e exteriorização das normas sociais.

Elias rejeita a idéia de que a sociedade seja uma instância supra-individual e metafísica. Em vez de trabalhar numa chave durkheimiana dos fatos sociais e da problemática da coerção subjacente a este conceito, opta por usar termos ou "noções vazias" como cadeias de interdependência, redes, ou simplesmente uma noção extensiva de jogo como mecanismo de constituição e afirmação das interações sociais. ${ }^{21}$ A qualidade coletiva dos fenômenos reside nas ações recíprocas entre indivíduos que tensionam a cadeia de interdependência ou uma competição, de maneira não planejada, ao mesmo tempo em que estão sujeitos a ela. Aqui parece que as analogias cessam na medida em que uma sociedade é, de fato, um jogo para o autor, um jogo extensivo jogado por $\boldsymbol{n}$ indivíduos.

Inicialmente, a metáfora da rede, comparada a redes humanas, foi utilizada pelo próprio Elias para matizar a dicotomia durkheimiana entre indivíduo e sociedade:

[...] nem a totalidade da rede nem a forma assumida por cada um de seus fios podem ser compreendidas em termos de um único fio, ou mesmo de todos eles,

\footnotetext{
21 “[...] são noções 'vazias’ na acepção de que não possuem nenhum outro significado a não ser o de articularem o arcabouço e o andamento da narrativa analítica. Por conseguinte, esses conceitos esvaziados de potencial heurístico, ou melhor, carentes de autopropulsão cognitiva - se deixam preencher pelos conteúdos de sentido derivados das lutas sociais, ajustando as lentes de aproximação dos móveis centrais da competição em nível societário” (Miceli, 1999, p. 126).
}

Horizontes Antropológicos, Porto Alegre, ano 14, n. 30, p. 191-219, jul./dez. 2008 
isoladamente considerados; a rede só é compreensível em termos da maneira como eles se ligam, de sua relação recíproca [...]. Isso é apenas uma imagem, rígida e inadequada como todas as imagens desse tipo. Mas, como modelo de reflexão sobre as redes humanas, é insuficiente para dar uma idéia um pouco mais clara da maneira como uma rede de muitas unidades origina uma ordem que não pode ser estudada nas unidades individuais [...]. Talvez ele atenda um pouco melhor a seu objetivo se imaginarmos a rede em constante movimento, como um tecer e destecer ininterrupto de ligações [...]. (Elias, 1994, p. 35).

Parece ser a idéia de jogo, superando os limites físicos, que a metáfora da rede impõe àquela que melhor exprime as bases epistemológicas de sua sociologia, tal como apontam alguns de seus comentadores. Estamos no âmbito das configurações e aqui a noção extensiva de jogo como categoria gerativa dos comportamentos manifestos deve ser entendida tanto no plano dos fenômenos sociais empíricos quanto no plano conceitual, como um poderoso instrumento analítico. Assim, “o jogo é invocado para explicar a dimensão concorrencial das relações sociais” [...] "não é definido como um corpo de regras, mas como uma combinação móvel e específica de relações sociais reais” [...] os grupos não são coisas: tampouco são estáticos, apenas são reificados pela linguagem [...] (Garrigou, 2001, p. 77-78).

Diversa de outras análises, a perspectiva de Elias permite que se relacionem os fenômenos jogo e esporte não de modo dicotômico, mas, antes, como um continuum, cujas propriedades definidoras tanto do jogo quanto do esporte são balizadas por um amplo processo identificado como a parlamentarização multipolar ocorrida na vida pública nas sociedades ocidentais. Assim, a constituição das configurações esportivas esteve orientada, mas também orientou o processo de civilização e parlamentarização da vida pública na criação das mediações institucionais reguladoras das interações sociais.

Porém, é sobre uma teoria geral da sociabilidade, problemática que sustenta a dinâmica das normas sociais, que quero me ater um pouco mais aqui como contribuição original para se compreender as regras do futebol do ponto de vista da sociologia do autor. Elias contrapõe a tendência "juralista” em conceber as normas sociais numa universalidade moral abarcada num único conjunto possível. Reconhecendo, obviamente, a ubiqüidade dessas instâncias regulativas da vida social, leva em consideração os níveis distintos de configurações através das quais se realiza a sociabilidade. Nesse sentido, apreendemse nas variações possíveis de configurações os níveis de interiorização e 
exteriorização a que estão submetidas as normas sociais pelos agentes. Embora não raramente seja censurada pelo seu escopo ambicioso de análise ao tratar do processo de constituição das sociedades ditas modernas ou "complexas”, sua teoria revela uma capacidade de percepção dos matizes e mediações que a expressão processo civilizatório tende a obscurecer numa leitura menos atenta de sua obra. Diria mesmo que se trata de uma perspectiva mais relativista que se intromete no seu projeto de sociologia histórica.

$\mathrm{O}$ autor distingue diferentes tipos de normas sociais que poderiam estar reagrupadas em níveis. Ele destaca ao menos dois: leis morais genéricas, que prescrevem os comportamentos individuais esperados dentro de uma dada "economia psíquica” e um outro nível que revelaria, de maneira mais dinâmica, as relações sociais próximas às regras de um jogo, que constituem o torvelinho dos grupos sociais que se fazem, se autonomizam ou se desfazem continuamente no fluxo permanente das interdependências. ${ }^{22}$

A "economia psíquica”, que orienta a capacidade dos indivíduos de se reagruparem, estabelecendo relações sociais duradouras numa sociedade moderna, pressupõe a convergência de três condições dadas pelo processo civilizatório: a de que o homem seja equilibrado, de que seja moderado e de que seja evoluído. O equilíbrio se refere ao ajuste entre motivações individuais e a estrutura social; a moderação se refere a um autocontrole na interiorização das formas de poder ajustadas à sociedade "civilizada”, controle nas expressões, gestos, ardores. A evolução se refere ao sentido do reconhecimento dos seus semelhantes na condução de uma noção de pessoa legitimada socialmente.

Levando-se em conta a dinâmica dos jogadores em campo e as regras que os prescrevem, para além da normalização da competição, estas podem ser compreendidas também como um sistema de etiquetas, delineando um decoro esportivo muito significativo para pensar os processos de aceitação ou rejeição de determinadas condutas, obviamente portadoras de valores de classe, étnicos etc. Uma análise dos decoros esportivos, que se alteram com as novas configurações de um futebol em constante processo de mudança, contribuiria sobremaneira para sintonizar muitas das análises que recortaram a temática do futebol a partir das biografias de determinados jogadores. Chamo a atenção para as condutas individuais desviantes, contestatórias, polêmicas, que

${ }^{22}$ Conforme Coury (2001). 
conferem às atitudes aparentemente esporádicas um tratamento sociológico no sentido da internalização ou não das demandas materiais e simbólicas a que estão continuamente sujeitos nas esferas esportivas. Esta perspectiva centrada na noção de indivíduo pode também revelar as mudanças relevantes nas definições de "futebol força" e "futebol arte" como capacidades individuais e coletivas no exercício das técnicas e das qualidades sensíveis que ajustam os jogadores numa ou noutra categoria e representação.

A tensão no interior da economia psíquica instituída no domínio esportivo atual, revelada na valorização do autocontrole e do equilíbrio da parte dos jogadores, não raramente tem concorrido com as características dadas pelo talento na formação dos índices que orientam o destino e a visibilidade das carreiras profissionais. Por exemplo, jogadores de alta qualidade técnica, mas violentos em campo ou polêmicos e controversos em relação às atitudes extra campo tem sofrido sanções dentro dos parâmetros do decoro do futebol atual, fatores que pesam na sua valorização dentro do mercado futebolístico de atletas.

A legitimidade e o sucesso na carreira esportiva seguem demandando por uma maior interiorização tanto das regras que orientam e instruem os jogadores para a competição dentro de campo quanto para o jogo das normas e decoros sociais fora dele. Fatores que alteram as percepções e a auto-imagem do futebol brasileiro como índice identitário. O tipo de normas das “leis morais” seria tomado como estável e suficientemente generalizado, perceptível, sobretudo na ação dos indivíduos e, por isso mesmo, caracterizado pelo seu alto grau de interiorização. Não se trata de nenhum viés psicologizante da teoria ou expressão pura de representações individuais, mas um conjunto de preceitos que, uma vez interiorizados numa escala coletiva, geradores de um habitus, extravasam as configurações mais particulares que se formam continuamente..$^{23}$

Já as normas do tipo das regras de jogo estariam centradas nos grupos e nas experiências a que nos submetemos ao participar de várias configurações possíveis (grupos de amigos, grupos profissionais, grupos de lazer, grupos familiares, etc). Mas, insisto não se tratar de uma tipologia, mas de níveis variados de interiorização das normas que facultam a navegação social de indivíduos e grupos pela sociedade:

\footnotetext{
${ }^{23}$ A “arte de reagrupar-se” imposta a todos os indivíduos, deve levar em consideração, primeiro, uma produção da semelhança, segundo, a normalização dos comportamentos e, em terceiro, a localização dos grupos, que efetiva as relações mais face a face. A propósito, consultar Coury (2001).
}

Horizontes Antropológicos, Porto Alegre, ano 14, n. 30, p. 191-219, jul./dez. 2008 
uma análise mais profunda das estratégias de entrelaçamento de indivíduos em grupos revela, geralmente, normas de vários níveis - normas dentro de normas ou regras dentro de regras - que podem mudar de acordo com novos desenvolvimentos e experiências na sociedade. (Elias; Dunning, 1992, p. 156).

Retomo as restrições que Elias faz às visões que tendem a reduzir as normas sociais a conjuntos autônomos de preceitos para impor também às regras do futebol estes níveis de interiorização verificados para as normas e valores vigentes em qualquer sociedade, uma vez que, sendo de mesma natureza que outras normas ou regras de jogo, contribuiriam também para estabelecer os contornos de uma teoria da sociabilidade. Ou seja, tomar as regras como um tema menor ou apartá-las das análises em razão das opções que privilegiam o estudo das dimensões simbólicas do futebol seria incorrer, mais uma vez, num deslize de conseqüências sérias para a ambição totalizante impregnado no método antropológico. Assim, no plano teórico

as normas podem seguir também modelos que constituem um nível inferior de generalidade e um tipo de abstração tal como as regras de um jogo. Não existe razão, exceto no âmbito de uma tradição filosófica não verificada, que permita aceitar que menor generalidade significa exatamente o mesmo que menor valor epistemológico ou científico. (Elias; Dunning, 1992, p. 154).

A sugestão é a de que o próprio conjunto das regras do futebol confirme esses níveis, o que, de certo modo, o singulariza em relação às regras de outras modalidades esportivas. Aplica-se o modelo geral das normas para o conjunto das regras do futebol, pois o alto grau de expansão da sua prática elevara determinadas regras a uma generalidade incomparável no domínio esportivo, o que certamente extravasa o conjunto de praticantes da modalidade esportiva, pois não há quem não reconheça ao menos uma de suas regras, a bola de futebol, regra II, por exemplo.

Embora muito diferenciadas entre si, tal como pudemos observar nos dois exercícios anteriores - algumas definindo os elementos do jogo e outras o processo do jogo ${ }^{24}$-, a rigor, na perspectiva de Elias, não se pode estabelecer uma

${ }^{24}$ Conforme sugestão de Vogel (1982). 
hierarquia determinante dentro do conjunto das regras que defina a natureza competitiva. Pois, esta natureza reside mais na concatenação do que nas características particulares de cada uma, embora denunciem variações no processo de interiorização, por indivíduos e grupos, a que são continuamente submetidas: reconhecer uma bola de futebol não implica que se compreenda a lei do impedimento. Desse modo:

Elias convida a analisar os objetos, os imóveis, os rituais e as normas de conduta que, impondo-se nos locais freqüentados pelos [por estes] indivíduos, permitenos que nos aproximemos o mais possível do que eles são socialmente, de que percebem e de que os sensibiliza. (Coury, 2001, p. 129).

Apenas para terminar esta última movimentação do sumário do livro de regras, gostaria de mencionar uma das regras que explicitamente incide sobre a pacificação dos comportamentos e do decoro esportivo entre os indivíduos em campo, tema caro à abordagem configuracional. Como apontei anteriormente (Toledo, 2002a), as controvérsias em torno da aplicação da regra "quente” XII, nos primórdios da difusão do futebol em alguns centros urbanos no Brasil, por volta das primeiras décadas do século XX (sobretudo no que dizia respeito à compreensão do uso legal do tranco como recurso lícito e plástico na disputa das jogadas ${ }^{25}$ ) pode ser compreendida como uma competição mais ampla no domínio das sensibilidades e interiorização das normas esportivas e sociais.

A interiorização do uso do tranco pelos diversos grupos que primeiro se aventuraram na prática esportiva deu-se numa esfera de diferenciação social tensa e negociada: regras dentro de regras. As tentativas de impor a universalização da prática do futebol e de suas regras confrontaram-se aos valores de grupos sociais distintos e aos regimes de alteridade no interior da sociedade complexa. Os usos do corpo como suporte das normas, mas também como gerador e matriz de etiquetas sociais e condutas particulares, enunciaram

\footnotetext{
${ }^{25} \mathrm{O}$ tranco consiste numa disputa pela posse da bola valorizando o contato físico por intermédio dos ombros, somente. Tal recurso é utilizado quando a bola está numa posição mais ou menos eqüidistante de dois jogadores, simultaneamente em movimento de corrida. Esta discussão sobre o tranco está contida numa análise mais detida sustentada pela hipótese da correlação entre o processo de universalização das regras do futebol e a variação nos estilos de jogar em Toledo (2002a).
}

Horizontes Antropológicos, Porto Alegre, ano 14, n. 30, p. 191-219, jul./dez. 2008 
os rumos de um processo não planejado que confirmaria o futebol como prática esportiva de grande alcance social e simbólico no Brasil.

Se, na letra fria da prescrição da regra, o tranco podia ser notado como mais um recurso posto em ação no processo de ampliação dos níveis de emoção do jogo, o embate não silenciado dos corpos dos jogadores em disputa, dado a crescente mistura de indivíduos de diferentes classes sociais com a intensificação da profissionalização após os anos 1930, atribuíam ao recurso do tranco significados distintos, mas que, paulatinamente, acabariam contribuindo para o uso alargado da esquiva e do drible como marcas distintivas de um mesmo futebol.

A elite desportista, ainda presa aos desígnios de um processo de civilização que censurava o uso do corpo como linguagem, o condenava como simples falta de decoro; de outro lado, muitos desportistas oriundos das classes populares, sobretudo de origem negra, esquivavam-se ou evitavam o uso do tranco, pois o enfrentamento direto com os possíveis egressos das elites em campo de jogo multiplicava ainda mais as formas do preconceito, agora transfiguradas no domínio dos embates esportivos.

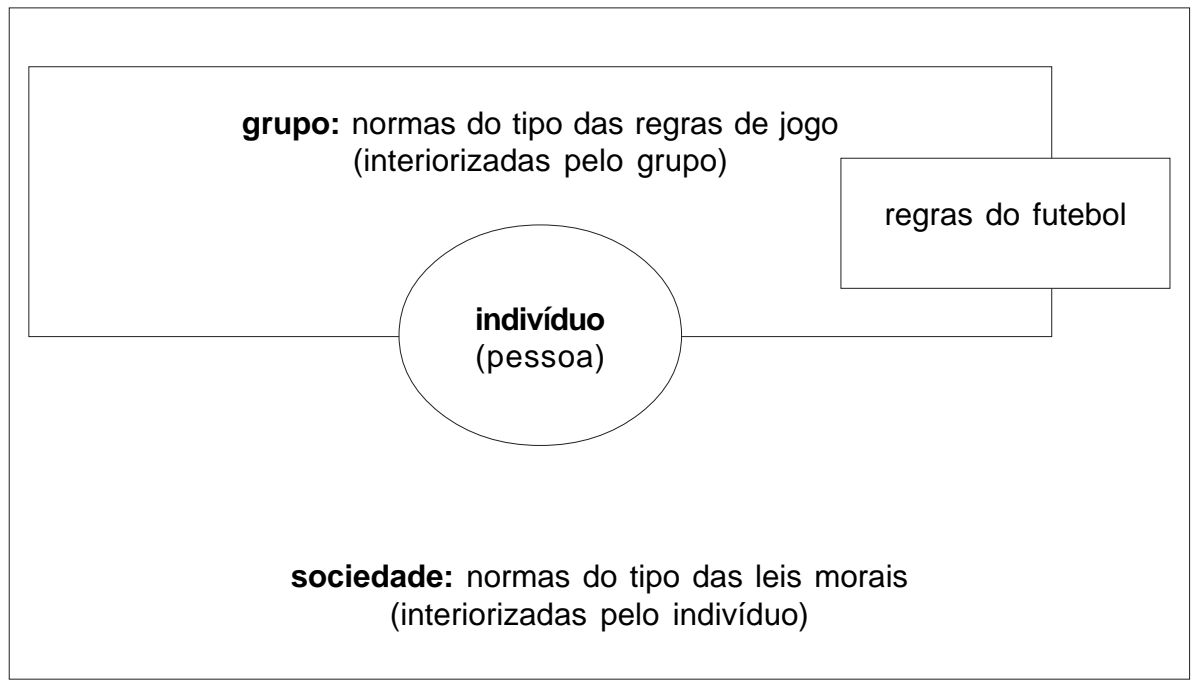

Representação gráfica da justaposição das normas sociais proposta por Norbert Elias. 


\section{A regra éclara ${ }^{26}$}

As analogias conceituais feitas acima permitiram verificar algumas estratégias metodológicas e teóricas de abordagem das regras do futebol. Manipulei livremente o sumário do livro de regras com o intuito de iluminar nele classificações e tipologias há muito reificadas nas análises, mas que seguem orientando, não raramente de maneira instrumental, inúmeras abordagens sobre os fenômenos esportivos, em particular o futebol.

Movimentar as categorias nativas neste carrossel conceitual, correndo o risco de um ecletismo desnecessário, sinaliza para a necessidade de um enfoque multidirecional de um fenômeno complexo e processual, que são os esportes. Enfoquei neste artigo as regras do futebol como uma instância constitutiva que está no epicentro dessa complexidade. Nesse sentido, as regras condensariam historicidades, processos e simbolizações e uma aproximação desses preceitos ao mundo das ações sociais, do vivido e das classificações simbólicas dentro do campo esportivo as tornaria menos suscetíveis às freqüentes reificações a que são submetidas.

\section{Referências}

BEVILAQUA, C. O consumidor e seus direitos: um estudo sobre conflitos no mercado consumidor. Tese (Doutorado Antropologia Social)-Universidade de São Paulo, São Paulo, 2002.

CAILLOIS, R. O homem e o sagrado. Lisboa: Edições 70, 1988.

COURY, G. Norbert Elias e a construção dos grupos sociais: da economia psíquica à arte de reagrupar-se. In: GARRIGOU, A.; LACROIX, B. (Org.). Norbert Elias: a política e a história. São Paulo: Perspectiva, 2001. p. 123-144.

${ }^{26}$ Bordão de Arnaldo César Coelho, ex-árbitro dos quadros da Fifa, atualmente comentarista de arbitragem nas transmissões futebolísticas pela Rede Globo de Televisão. 
DAMATTA, R. Esporte na sociedade: um ensaio sobre o futebol brasileiro. In: DAMATTA, R. et al. (Org.). Universo do futebol. Rio de Janeiro: Pinakotheke, 1982. p. 19-42.

DAMATTA, R. et al. (Org.). Universo do futebol. Rio de Janeiro: Pinakotheke, 1982.

DAMO, A. S. Do dom à profissão: a formação de futebolistas no Brasil e na França. São Paulo: Hucitec, 2007.

DURKHEIM, É. Representações individuais e representações coletivas. In: DURKHEIM, É. Sociologia e filosofia. São Paulo: Editora Forense, 1970. p. 13-42.

ELIAS, N. A sociedade dos indivíduos. Rio de Janeiro: Jorge Zahar, 1994.

ELIAS, N.; DUNNING, E. O lazer no espectro do tempo livre. In: ELIAS, N.; DUNNING, E. Em busca da excitação. Lisboa: Difel, 1992. p. 139-186.

ERIBON, D.; LÉVI-STRAUSS, C. De perto e de longe. Rio de janeiro: Nova Fronteira, 1989.

FLORENZANO, J. P. A democracia corinthiana: práticas de libertação no futebol brasileiro. Tese (Doutorado em Ciências Sociais)-Pontifícia Universidade Católica, São Paulo, 2003.

FRANCISCON, M. Futebol: regras e legislação. 12. ed. São Paulo: Prol, 1996.

GARRIGOU, A. O grande jogo da sociedade. In: GARRIGOU, A.; LACROIX, B. (Org.). Norbert Elias: a política e a história. São Paulo: Perspectiva, 2001. p. 65-88.

GAY, P. O cultivo do ódio. São Paulo: Companhia das Letras, 1995.

GOLDMAN, M. Lévi-Strauss e os sentidos da história. Revista de Antropologia, v. 42, n. 1-2, p. 223-238, 1999.

HUIZINGA, J. Homo ludens. São Paulo: Perspectiva, 1993.

LEFORT, C. As formas da história. São Paulo: Brasiliense, 1990. 
LÉVI-STRAUSS, C. Os limites do conceito de estrutura em etnologia. In: BASTIDE, R. (Org.). Usos e sentidos do termo estrutura. São Paulo: Editora da Universidade de São Paulo: Herder, 1971. p. 33-39.

LÉVI-STRAUSS, C. A via das máscaras. Lisboa: Editorial Presença, 1979.

MAUSS, M. Sociologia e antropologia. São Paulo: Epu: Edusp, 1974. 2 v.

MICELI, S. Norbert Elias e a questão da determinação. In: WAIZBORT, L. (Org.). Dossiê Norbert Elias. São Paulo: Edusp, 1999. p. 113-127.

MOURA, G. de A. O Rio corre para o Maracanã. Rio de Janeiro: Fundação Getúlio Vargas Editora, 1998.

NEVES, L. F. B. Na Zona do Agrião, algumas mensagens ideológicas do futebol. In: DAMATTA, R. et al. (Org.). O universo do futebol. Rio de Janeiro: Pinakotheque, 1982. v. 1, p. 43-57.

PEREIRA, L. Football Mania: história social do futebol carioca (1902-1938). São Paulo: Nova Fronteira, 2000.

PINHEIRO FILHO, F. Mente do Todo: o encontro da sociologia durkheimiana com a questão do tempo. Dissertação (Mestrado em Sociologia)-Universidade de São Paulo, São Paulo, 1996.

RADCLIFFE-BROWN, A. R. Estrutura e função na sociedade primitiva. Petrópolis: Vozes, 1973.

SAHLINS, M. O “pessimismo sentimental” e a experiência etnográfica: por que a cultura não é um “objeto” em via de extinção (parte I). Mana, v. 3, n. 1, p. 41-73, 1997a.

SAHLINS, M. O “pessimismo sentimental” e a experiência etnográfica: por que a cultura não é um “objeto” em via de extinção (parte II). Mana, v. 3, n. 2, p. 103-150, 1997b.

TÉCNICOS: deuses e diabos da terra do futebol. São Paulo: Sesc, 2002. Catálogo coletivo.

TOLEDO, L. H. Lógicas no futebol. São Paulo: Hucitec: Fapesp. 2002a. 
TOLEDO, L. H. Futebol e teoria social: aspectos da produção acadêmica (19822002). BIB: Revista Brasileira de Informação Bibliográfica, v. 52, p. 133-165, 2002b.

VENBLEN, T. A teoria das classes ociosas. São Paulo: Pioneira, 1965.

VIANNA, F. de L. B. A bola, os "brancos" e as toras: futebol para índios Xavante. Dissertação (Mestrado em Antropologia)-Faculdade de Filosofia, Letras e Ciências Humanas, Universidade de São Paulo, São Paulo, 2002.

VELHO, G.; VIVEIROS DE CASTRO, E. O conceito de cultura e o estudo das sociedades complexas: uma perspectiva antropológica. Artefato: Jornal de Cultura, ano 1, n. 1, 1978.

VIVEIROS DE CASTRO, E. O conceito de “sociedade” em antropologia: um sobrevôo. In: VIVEIROS DE CASTRO, E. A inconstância da alma selvagem - e outros ensaios de antropologia. São Paulo: Cosac \& Naify, 2002. p. 297-316.

VOGEL, Arno. O momento feliz: reflexões sobre o futebol e o ethos nacional. In: DAMATTA, R. et al. (Org.). O universo do futebol. Rio de Janeiro: Pinakotheque, 1982. v. 1, p. 75-115. 